\title{
Pulmonary alveolar proteinosis in an AIDS patient without concurrent pulmonary infection
}

\author{
ALlen T LIU MD, LIL J MIEDZINSKI MD, ERIC VALLIERES MD, DAVID C RAYNeR MD, \\ DALE C LIEN MD \\ Departments of Medicine, Pathology and Thoracic Surgery, University of Alberta, \\ Edmonton, Alberta
}

\begin{abstract}
AT LiU, LJ Miedozinski, E VAllieres, DC RAYNer, DC LIEN. Pulmonary alveolar proteinosis in an AIDS patient without concurrent pulmonary infection. Can Respir J 1995;2(3):183-186.

Patients with acquired immunodeficiency syndrome (AIDS) are potentially at increased risk for developing secondary pulmonary alveolar proteinosis because of underlying immunosuppression and frequent opportunistic lung infections. This condition, however, has been diagnosed uncommonly in these patients and, with the exception of one previously reported case, only in the presence of concurrent pulmonary infection. The case of a 35-year-old male with AIDS who was found on open lung biopsy to have pulmonary alveolar proteinosis without evidence of associated lung infection is presented.
\end{abstract}

Key Words: Acquired immune deficiency syndrome'. Pneumocystis carinii pneumonia, Pulmonary alveolar proteinosis

\section{Protéinose alvéolaire sans infection pulmon- aire concomitante chez un patient sidatique}

RÉSUMÉ : Les patients souffrant du syndrome d'immunodéficience acquise (SIDA) sont potentiellement à plus grand risque de développer une protéinose alvéolaire secondaire à cause d'une immunodépression sous-jacente et de fréquentes infections pulmonaires opportunistes. Cependant, cette affection a rarement été diagnostiquée chez ces patients et, à l'exception d'un cas précédemment rapporté, seulement en présence d'une infection pulmonaire concomitante. Le cas d'un homme de 35 ans atteint du SIDA dont la biopsie pulmonaire ouverte a révélé une protéinose alvéolaire sans évidence d'une infection pulmonaire concomitante est présenté.
$\mathrm{P}$ ULMONARY ALVEOLAR PROTEINOSIS (PAP') IS AN UNCOMmon condition that may be either primary (idiopathic), arising in an otherwise healthy patient, or secondary, where it occurs in a setting of altered immunity or concurrent lung infections. Patients with acquired immunodeficiency syndrome (AIDS) should be at risk for this disorder al- though it has rarely been reported in this population (1). Previous reports of PAP in AIDS patients have usually been in the presence of an active or recent infection. We present a case without an associated lung infection which, to our knowledge, hils been reported only once previously (2). 


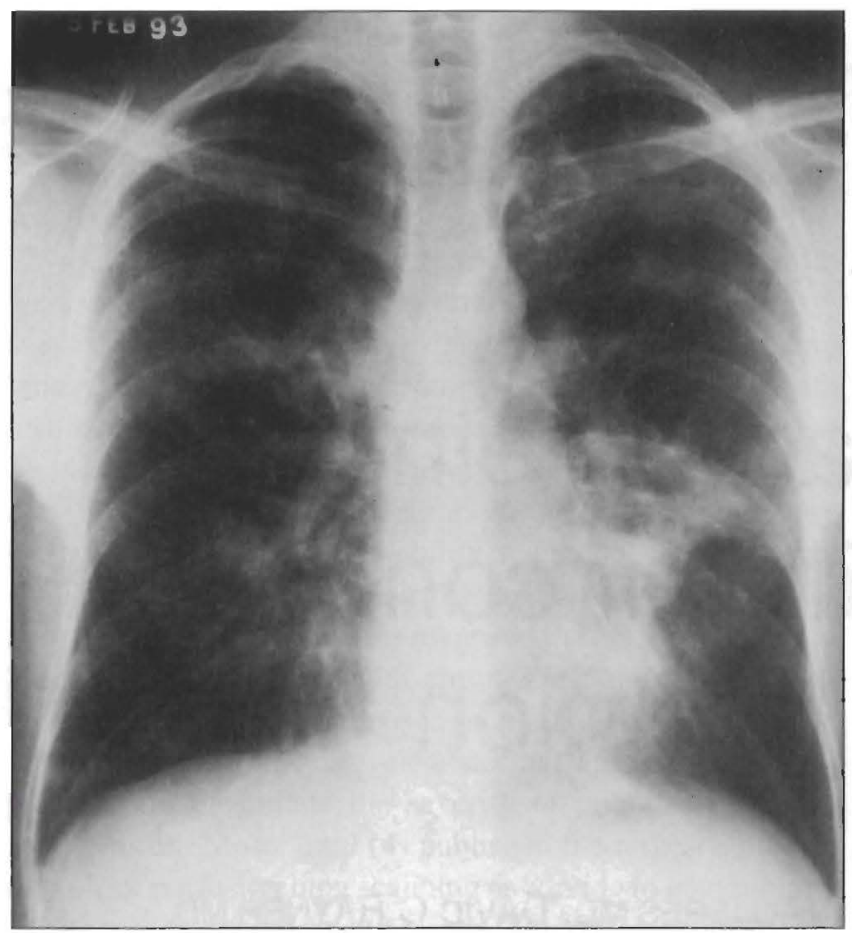

Figure 1) Chest radiograph showing poorly defined airspace consolidative changes in both lung fields, more predominant in the left mid-lung zone. The radiographic results remained unchanged from December 1992 to February 1993

\section{CASE PRESENTATION}

A 35-ycar-old homosexuil male was found to be positive for the human immunodeficiency virus (HIV) in 1987. He had documented Pneumocystis carinii pneumonia (PCP) in March 1991 and again in April 1992. Because of adverse eflects from pentamidine and sulpha, he was maintained on dapsone as prophylaxis against PCP. In addition, he had previously developed cutaneous Kaposi's sarcoma, which wals treated with local irradiation. esophageal candidiasis treated with fluconazole, and cutancous herpes simplex infection for which acyclovir was prescribed. In July 1992, because of at two-week history of nild dyspnea and nonproductive cough without significant radiographic change, a bronchoalveolar livage (BAL) was performed which failed to demonstrate any bacterial, viral or fungal organisms, including $P$ carinii. These symptoms subsided spontaneously without specific treatment.

He presented again in December 1992 with a four-month history of progressive dyspneil on exertion, nonproductive cough, fever, anorexia and fatigue. His chest radiograph and computerized tomographic (CT) scan are shown in Figures 1 and 2, respectively. He underwent fibreoptic bronchoscopy with BAL and transbronchial lung biopsies from the lingula. No endobronchial Kaposi's sarcomat was seen and there was no evidence of bacterial, viral, fungal, mycobacterial or pneumocystis organisms in the BAL fluid. Analysis of the differential cell count of the BAL showed greater than $80 \%$ macrophages and the biopsies failed to reveal any inflammatory or neoplastic changes.

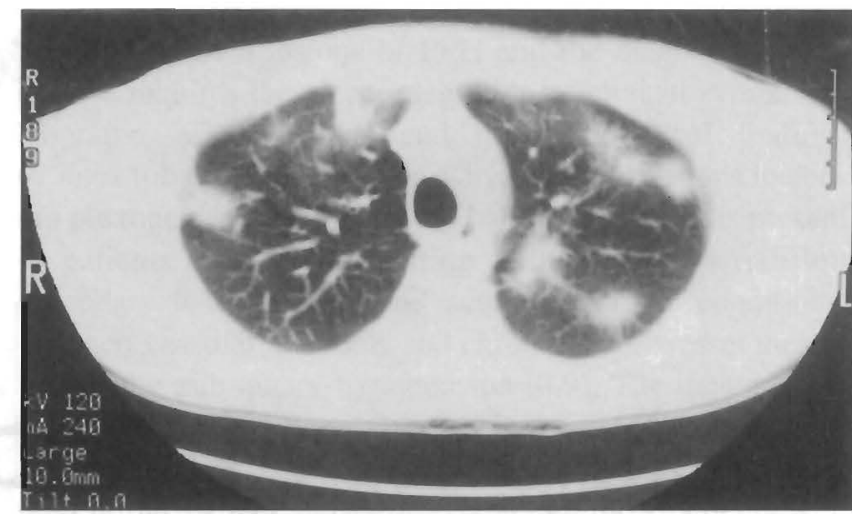

Figure 2) Computerized tomographic section showing patchy airspace consolidation. The mediastinum and hila were free of lymphadenopathy

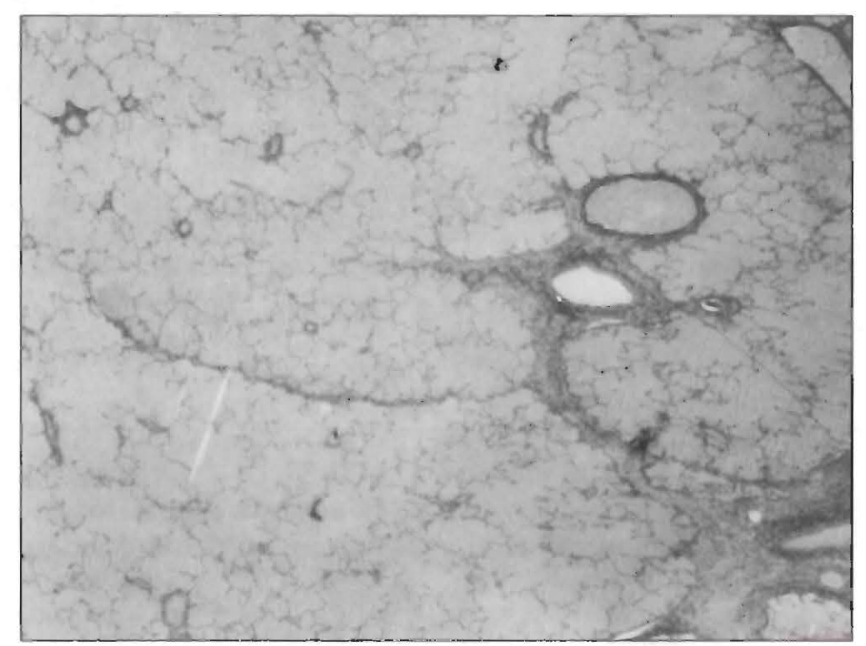

Figure 3) Open lung biopsy stained with hematoxylin and eosin. Airspaces are obliterated by amorphous eosinophilic material with no cellular infiltrate. Magnification $\times 13.6$

His symptoms and radiographic changes persisted unaltered and in February 1993 an open biopsy of the lingulit was performed. Paraffin sections showed obliteration of the distal airspaces by eosinophilic amorphous material which stained variably positive with periodic acid-Schiff (PAS) (Figure 3). No inflammatory infiltrate, no specific viral changes and no interstitial process was seen. Multiple sections examined with Gomori's methenamine silver (GMS), Ziehl-Neelsen, Fite and Gram stains revealed no pathogenic organisms and an immunoperoxidase stain for cytomegalovirus (Chemicon, California) was negative. In addition, routine cultures of the biopsy tissue for bacteria, viruses, fungi and mycobacteria were negative.

No active treatment was instituted and at his follow-up two months later, he reported no new symptoms but was still dyspneic after walking one block. Six weeks later he was readmitted to hospital because of increasing dyspnea, cough and hypoxemia. Chest radiograph revealed airspace disease in upper lung zones bilaterally. Bronchoscopy with BAL was undertaken and the results were diagnostic of PCP on this 
occasion. The patient intially improved with treatment and was discharged, but one weck litler required readmission due 10 worsening dyspnea, cough and hypoxemia. Chest radiograph demonstrated more dense consolidation dilfusely. His condition deteriorated rapidly and he subsecyuently died. An autopsy was not performed.

\section{DISCUSSION}

PAP was initially described in 1958 by Rosen et al (3). Pathologically, the characteristic change is an accumulation of amorphous PAS-positive phospholipids and proteins in the alveoli, with preservation of the interstitium. Various theoric: of its pathogenesis have been proposed that revolve around a disturbance of alveolar surfactant homeostasis, with a defect in the removal or resorption of surlactant being the most favoured (4). The two classical symptoms are chronic cough. which is usually nonproductive, and progressive dyspnea on exertion. Less common symptoms include fover, weight loss, fatigue, chest pain and hemoptysis. Chest radiographs show nonspecific alveolatr infilltates without mediastinal lymphatdenopathy. CT scans characteristically demonstrate a grey homogeneous appearance of the lungs related to the underlying consolidative process. Overlying this is a branching pattern of white linear structures representing the thickened interlobular septa between the secondary lobules. This results in an overall 'crazy paving' appearance typical of alveolar proteinosis (5). In contrast, PCP is a diffuse airspace disease that appears as focal areas of ground glass opacification on CT through which pulmonary vessels can still be identified. Kaposi's sarcoma classically takes on a nodular pattern in the perivascular and peribronchial regions (6). Gallium scan is negative in PAP. Pulmonary function testing Iypically demonstrates a restrictive defect with decreased lotal lung capacity and vital capacity, along with a low diffusing capacity. The diagnosis may be made on BAL specimens due to the presence of granular acidophilic phospholipid material, which stains positively with PAS and has a characteristic ultrastructural appearance (7). Transbronchial or open lung biopsy may be required for diagnosis. Biopsy may also be required when the possibility of a concurrent process, particularly infection, rematus in the differential diagnosis. PAS staining was not performed on the BAL fluid in this patient becaluse the diagnosis was not suspected.

Two forms of this pulmonary disorder have heen described, with primaty or classic PAP occurning without an associated caluse, while secondary PAP (or alveolar phospholipidosis) is reported to be linked to certain conditions, most importantly lung infections $(8-I 0)$ and immunodeficioncy states (11). It seems that AIDS patients should be at risk for this latter form of PAP (1). Howvever, to our knowkedge, only nine cases of PAP have been reported in this patient population, in eight of whom it was associated with at simultaneous opportunistic lung infection. PCP wats found in six cases (7). tuberculosis in one case (12), and PCP together with disseminated cytomegalovirus in one casc (12).

The relationship botween lung infection and PAP in AIDS patients remains unclear. It is still possible that infection may have been an important part of the pathogenetic process in our patient. Although we were unable to demonstrate an associated infection, our patient did have previous PCP, which could have an unknown pathogenetic role. Of further concern is that our patient relied on a less effective agent, dapsone, as prophylaxis against PCP.

Dapsone is used for both primary and secondary PCP prophylaxis, especially in those who are intolerant of trimethoprim-sulfamethoxazole, as was the case in our patient. Dapsone is felt to be as effective as aerosolized pentamadine, which is also used as prophylaxis against PCP and mat be associated with a lower diagnostic yield for $P$ carinii on $\mathrm{BAL}$. (13), but this issue has not been studied with dapsone. However, the diagnostic gold standard is a lung biopsy and our patient did have transbronchial and open lung biopsies while he was on dapsone, but neither demonstrated $P$ carinii or any other microorganisms. To ensure this, we carefully examined approximately $8 \mathrm{~cm}^{2}$ of GMS staned tissuc from several blocks of the open lung biopsy and found no organisms. We therefore believe that our patient is the second reported case of PAP described in an AIDS patient without a concurrent or recent pulmonary infection.

Furthermore, superinfections are known complicallons of PAP (4). Our patient was found to halve PCP 3.5 months alter the diagnosis of PAP, with progressive deterioration until his demise. Indeed, superimposed infections and respiratory l'ailure from the proteinosis are the lwo major causes of death from this disorder.

In spite of a $30 \%$ mortality from PAP noted before the era of lung lavage, spontaneous and complete remission is known to occur in 20 to $25 \%$ of patients (14). 1 lowever, there are no factors that accuratcly predict which patient will suc cumb, remit or respond to treatment. This uncertainty in the natural course of PAP in any given patient serves to account for the lack of a specific and well-defined set of indications for therapeutic intervention. Various objective criteria have been proposed, including arterial $\mathrm{PO}_{2}$ less than $65 \mathrm{mmHg}$. difference in partial pressures of oxygen in mixed alveolar gas and mixed arterial blood greater than $40 \mathrm{mml} g$, shumt fraction greatter than 10 to $12 \%$, and all confirmed histologi cal diagnosis $(15,16)$. However, the decision to recommend treatment is generally based on the extent to which PAP affects the patient in relation $\mathrm{t}$, his or her exercise tolcrance, lifestyle and occupation. That is, if the patient 's daily activities are limited by the symptoms, treatment may he appropriate (4).

Various treatment options were used in the past, including systemic corticosteroids and inhalational therapy with heparin. Irypsin or acetylcysteine, but they have largely been abandoned duc to their side effects and lack of proven efticalcy. Whole lung lavage is curently the therapy of choice and functions by mechanically removing the intratalveolar phospholipids. It is sale and effective in the majority of patticnts il performed by an cxperienced multidisciplinary team (4). However, secondary PAP, ats seen with concurrent pulmonary infection and/or underlying immunodeficiency. maly not 
have as favourable a response to whole lung lavage as primary PAP. Therefore it may be important that the diagnosis of primary PAP not be made unless the possible secondary causes have been excluded because therapy may be best directed at these causes initially. This underlies the need for histological examination of lung lissues in certain cases to obtain an accurate diagnosis, thus allowing appropriate therapy to be given.

\section{REFERENCES}

1. Israel RH, Magnussen CR. Are AIDS patients at risk for pulmonary alveolar proteinosis? Chest 1989;96:641-2.

2. Case Records of the Massachusetts General Hospital. N Engl J Med 1984;310:906-16.

3. Rosen SH, Castleman B, Liebow AA. Pulmonary alveolar proteinosis. N Engl J Med 1958;258:1 123-42.

4. Claypool WD, Rogers RM, Matuschak GM. Update on the clinical diagnosis, management and pathogenesis of pulmonatry alveolar proteinosis. Chest 1984;85:550-8.

5. Murch CR, Carr DH. Computed tomography appearances of pulmonary alveolar proteinosis. Clin Radiol 1989;40:240-3.

6. McLoud TC, Naidich DP. Thoracic disease in the immunocompromised patient. Radiol Clin North Am 1992;30:525-54.

7. Tran Van Nhieu J, Vojtek A, Bernaudin J, Escudier E, Fleury-Feith J. Pulmonary alveolar proteinosis associated with Pneumocystis carinii. Ultrastructural identification in bronchoalveolar lavage in AIDS and immunocompromised non-AIDS patients. Chest 1990;98:801-5.

8. Carlsen ET. Hill RB Jr, Rusvlands DT Jr. Nocardiosis and pulmonary alveolar proleinosis. Ann Intern Med 1964;60:275-81.

9. Hartung N, Salfelder K. Pulmonary alveolar proleinosis and

\section{CONCLUSIONS}

This case should alert clinicians to include PAP in their differential diagnosis in an AIDS patient who presents with an alveolar infiltrate accompanied by a nomproductive cough and exertional dyspnea. Although PAP is often associalted with a pulmonary infection in patients with AIDS, the absence of an identifiable organism does not appear lo preclude its diagnosis.

histoplasmosis: report of three cases. Virchows Arch A Pathol Anat 1975;368:281-7.

10. Steer A. Focal pulmonary alveolar proteinosis in pulmonary tuberculosis. Arch Pathol 1969;87:347-52.

11. Bedrossian CWM, Luna MA, Conklin RH, Miller WC. Alveolar proteinosis as a consequence of immunosuppression. A hypothesis based on clinical and pathological observations. Hum Pathol 1980;11(Suppl):527-35.

12. Ruben FL. Talamo TS. Secondary pulmonary alveolarr proteinosis occurring in two patients with acquired immunc deficiency syndrome. Am J Med 1986;80:1 187-90.

13. Jules-Elysee KM, Stover DE, Zaman MB, Bernard EM, Whitc DA. Aerosolized pentamadine: effect on diagnosis and presentation of Pneumocystis carimii pneumonia. Ann Intern Med 1990;1 12:750-7.

14. Davidson JM, MacLeod WM. Pulmonary alveolar proteinosis. Br J Dis Chest 1969;63:12-28.

15. Kariman K, Kylstra JA, Spock A. Pulmonary alveolar proteinosis: prospective clinical experience in 23 patients for 15 years. Lung 1984;162:223-31.

10. Rogers RM, Levin DC, Gray BA, Moseley LW Jr. Physiologic effects of bronchopulmonary lavage in alveolar proteinosis. Am Rev Respir Dis 1978;1 18:255-64. 


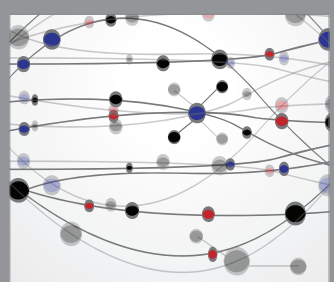

The Scientific World Journal
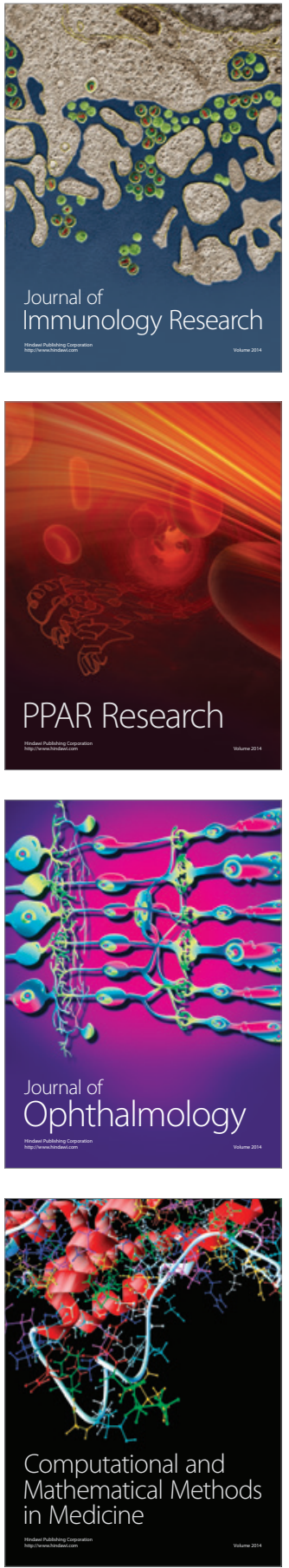

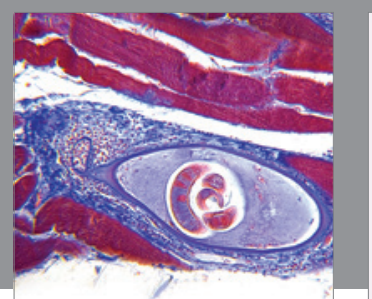

Gastroenterology Research and Practice

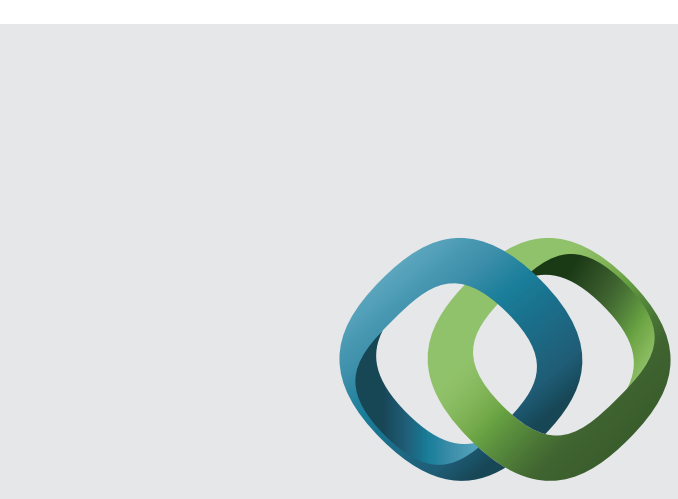

\section{Hindawi}

Submit your manuscripts at

http://www.hindawi.com
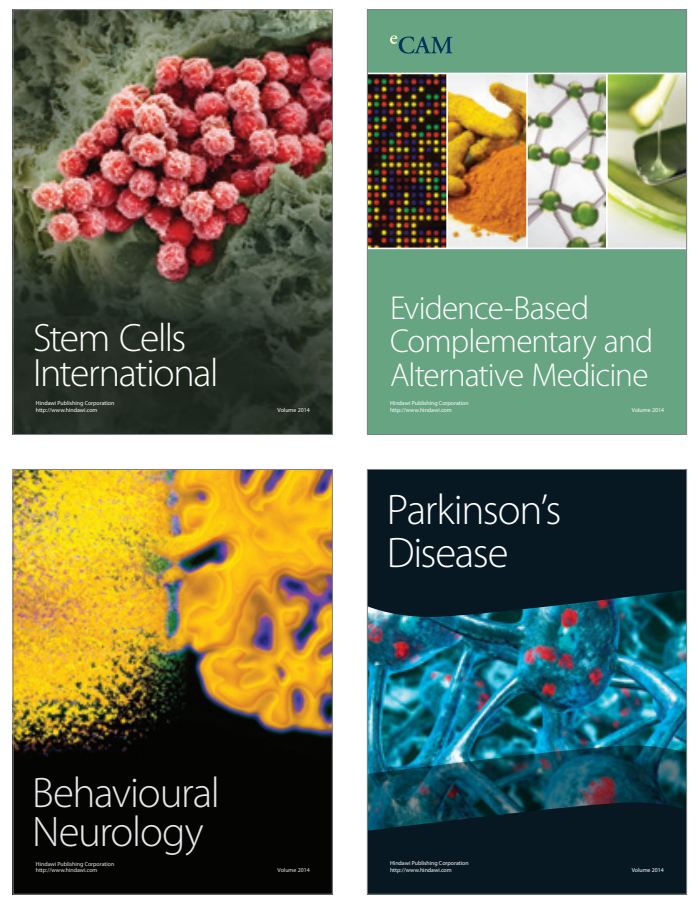
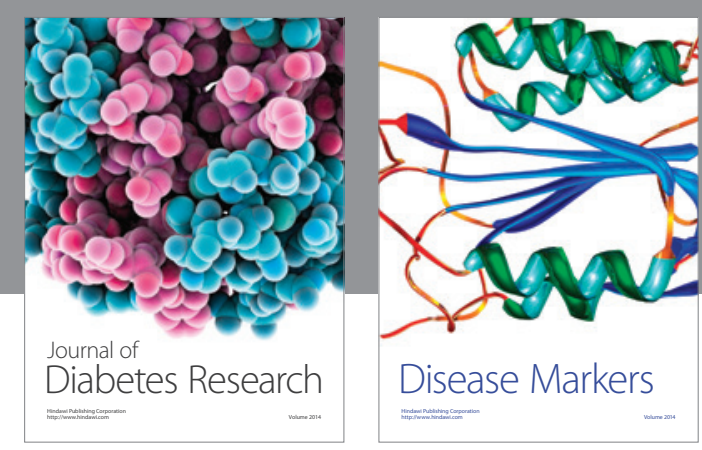

Disease Markers
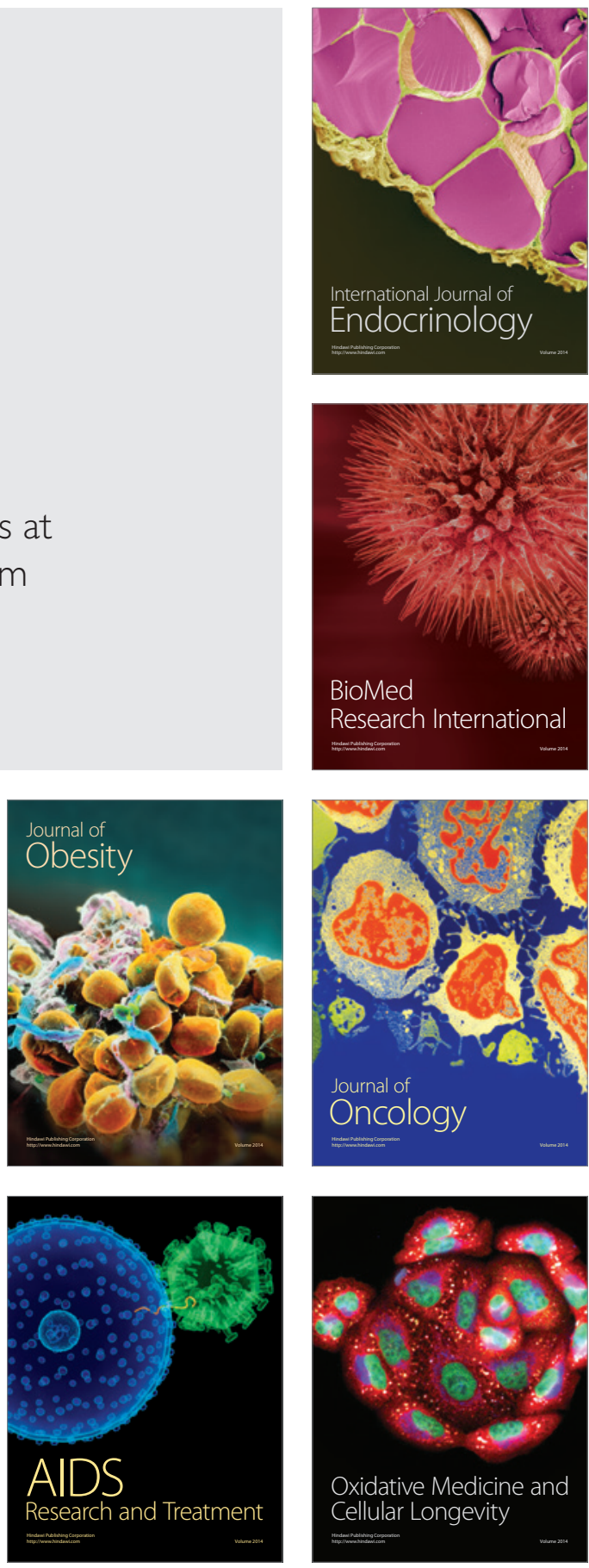